\title{
Ligands of boron in Pisum sativum nodules are involved in regulation of oxygen concentration and rhizobial infection
}

\author{
Reguera M ${ }^{1}$, Wimmer $\mathrm{M}^{2}$, Bustos $\mathrm{P}^{3}$, Goldbach HE ${ }^{2}$, Bolaños L ${ }^{1}$, Bonilla I ${ }^{1}$. \\ ${ }^{1}$ Departamento de Biología, Facultad de Ciencias, Universidad Autónoma de Madrid, \\ Darwin 2, 28049-Madrid, Spain, \\ ${ }^{2}$ Institute of Crop Science and Resource Conservation - Plant Nutrition, University of Bonn, \\ Karlrobert-Kreiten-Strasse 13, D-53115 Bonn, Germany \\ ${ }^{3}$ Departamento de Nutrición Vegetal, Estación Experimental de Aula Dei, Consejo Superior de Investigaciones Científicas, \\ Apartado 13034, 50080 Zaragoza, Spain
}

*L. Bolaños. Fax: +34913978344; e-mail: luis.bolarios@uam.es

\begin{abstract}
Boron (B) is an essential nutrient for N(2)-fixing legume-rhizobia symbioses, and the capacity of borate ions to bind and stabilize biomolecules is the basis of any $\mathrm{B}$ function. We used a borate-binding-specific resin and immunostaining techniques to identify B ligands important for the development of Pisum sativumRhizobium leguminosarum 3841 symbiotic nodules. arabinogalactan-extensin (AGPE), recognized by MAC 265 antibody, appeared heavily bound to the resin in extracts derived from B-sufficient, but not from Bdeficient nodules. MAC 265 stained the infection threads and the extracellular matrix of cortical cells involved in the oxygen diffusion barrier. In B-deprived nodules, immunolocalization of MAC 265 antigens was significantly reduced. Leghaemoglobin $(\mathrm{Lb})$ concentration largely decreased in B-deficient nodules. The absence of MAC 203 antigens in B-deficient nodules suggests a high internal oxygen concentration, as this antibody detects an epitope on the lipopolysaccharide (LPS) of bacteroids typically expressed in microaerobically grown R. leguminosarum 3841. However, B-deprived nodules did not accumulate oxidized lipids and proteins, and revealed a decrease in the activity of the major antioxidant enzyme ascorbate peroxidase (APX). Therefore, B deficiency reduced the stability of nodule macromolecules important for rhizobial infection, and for regulation of oxygen concentration, resulting in non-functional nodules, but did not appear to induce oxidative damage in low-B nodules.
\end{abstract}

Keywords:

borate complexes; leghaemoglobin; legume AGP-extensin; legume rhizobin symbiosis; APX 


\section{INTRODUCTION}

The work of Katherine Warington (1923) is considered the first showing that boron (B) is required for vascular plants. Since that early report and during the following 60 years, several 'postulated roles of B' for higher plant growth and development were described (cited by Parr \& Loughman 1983), although only cross-linking of apiose residues by B in the cell wall pectic polysaccharide rhamnogalacturonan II (RGII) has been convincingly demonstrated (O'Neill et al. 2001). Therefore, many of the numerous biochemical, physiological and anatomical effects of B deficiency in plants have often been considered secondary effects. However, several studies predict that borate might be important for the stability and function of other biomolecules not necessarily involved in structural roles. Shkolnik (1984) demonstrated that B deficiency resulted in the release and activation of several extracellular enzymes bound to membranes or walls in a latent form. Hu et al. (1997) isolated soluble B-polyol complexes responsible for phloem mobility of B. In bacteria, B is a component of the signalling molecule autoinducer AI-2 implicated in quorum sensing (Chen et al. 2002). Moreover, the discovery of in vitro binding of borate to adenylates (Ralston \& Hunt 2001) or to cyclic ribose (Ricardo et al. 2004), along with the evidence of B essentiality in animals (reviewed by Hunt 2007) and the interaction with plant membrane-associated proteins (Wimmer et al. 2009), point to important roles of B beyond RGII crosslinking in cell walls.

The capacity of boric acid and borate to react with hydroxyl groups from biomolecules is considered a key for understanding B functions (Bolaños et al. 2004), and research should now be focused on the discovery of B complexes in biological systems. Although analytical procedures have been improved, the low B concentrations in cells make it a difficult challenge. Further progress depends on new methodology with greater analytical capability and/or on the discovery of biological models enriched in B ligands, which are therefore highly dependent on the micronutrient. Such a model is available in legume root nodules, which contain several plant- and bacteria-derived glyco-conjugates (Kannenberg \& Brewin 1994; Brewin 2004; references therein) that could be potential B-interacting molecules. Development and function of legume nodules are indeed strongly inhibited by B deficiency (Bolaños et al. 1994, 2001; Bolaños, Brewin \& Bonilla 1996; Bonilla et al. 1997; Redondo-Nieto et al. 2007).

Many reports indicate that the B requirement is higher for growing plant organs than for mature ones (reviewed by Bell, Dell \& Huang 2002). Nodules are organs with stages of intense growth prior to maturation and senescence, and evidence that symptoms of B deficiency appear in nodules earlier than in other plant organs (Bolaños et al. 1994) is in line with a higher B content in nodules compared with roots or shoots (Redondo-Nieto et al. 2003). In this paper, we used a borate-binding-specific resin to extend the study of the roles of B in the legume-rhizobia symbiosis with the main goal of identifying potential ligands of B involved in pea (Pisum sativum) nodule development.

\section{MATERIALS AND METHODS}

\section{Growth of plants and inoculation}


Pea (P. sativum cv. Lincoln) seeds were surface sterilized with 70\% (v/v) ethanol for $1 \mathrm{~min}$ and 10\% (v/v) sodium hypochlorite for $20 \mathrm{~min}$, soaked for $4 \mathrm{~h}$ in sterile distilled water and then germinated on wet filter paper at $25^{\circ} \mathrm{C}$. After $4 \mathrm{~d}$, the seedlings were transferred to $2.7 \mathrm{~L}(30 \times 30 \times 30 \mathrm{~cm})$ plastic growth pots filled with perlite $(9$ seedlings per pot) and supplied with FP medium for legumes (Fahraeus 1957) as the nutrient solution ( $0.68 \mathrm{mM} \mathrm{CaCl}_{2}, 0.5 \mathrm{mM}$ $\mathrm{MgSO}_{4} \cdot 7 \mathrm{H}_{2} \mathrm{O}, 0.7 \mathrm{mM} \mathrm{KH}_{2} \mathrm{PO}_{4}, 0.68 \mathrm{mM} \mathrm{Na}_{2} \mathrm{HPO}_{4} \cdot 2 \mathrm{H}_{2} \mathrm{O}, 50 \mu \mathrm{M} \mathrm{Fe}-E D T A, 9.3 \mu \mathrm{M} \mathrm{H}_{3} \mathrm{BO}_{3}, 10.6 \mu \mathrm{M} \mathrm{MnSO}_{4} \cdot \mathrm{H}_{2} \mathrm{O}$, $0.7 \mu \mathrm{M} \mathrm{ZnSO}_{4} \cdot 7 \mathrm{H}_{2} \mathrm{O}, 3.2 \mu \mathrm{M} \mathrm{CuSO}_{4} \cdot 5 \mathrm{H}_{2} \mathrm{O}, 1 \mu \mathrm{M} \mathrm{Na}_{2} \mathrm{MoO}_{4} \cdot 2 \mathrm{H}_{2} \mathrm{O}, \mathrm{pH}$ 6.3-6.7). The nutrient solution was renewed every $3 \mathrm{~d}$.

To induce B deficiency, $\mathrm{H}_{3} \mathrm{BO}_{3}$ was removed from the nutrient solution. All solutions were prepared and stored in polyethylene containers previously demonstrated not to release $\mathrm{B}$ even under sterilizing conditions. The solutions and media were tested for B prior to using them, and no B was detected (detection limit was $0.02 \mu \mathrm{g} \mathrm{mL}^{-1}$ ). B concentration was determined using azomethine H at pH 5.1 (Wolf 1974) and a Technicon Automatic Analytical System (Tarry Town, NY, USA). To remove undetectable B traces, Amberlite IRA-743 (Sigma Chemical Co., St Louis, MO, USA) was added at a concentration of $1 \mathrm{~g} \mathrm{~L}^{-1}$ during preparation of nutrient solutions and growth media. This B-binding-specific resin strongly complexes boric acid and borate ions on its $N$-methylglucamine functional groups, with an adsorption capacity of up to $5 \mathrm{mg} \mathrm{B} \mathrm{g}^{-1}$ resin (Asad, Bell \& Huang 1997).

The plants were inoculated with $1 \mathrm{~mL}$ per seedling of about $10^{8}$ cells $\mathrm{mL}^{-1}$ Rhizobium leguminosarum bv. viciae strain 3841 , from an exponential growth phase culture in tryptone-yeast extract (TY) medium (Beringer 1974). Inoculated plants were maintained in a growth cabinet at $22{ }^{\circ} \mathrm{C}$ day $/ 18^{\circ} \mathrm{C}$ night temperatures with a $16 \mathrm{~h}$ photoperiod and an irradiance of $190 \mu \mathrm{mol} \mathrm{m}^{-2} \mathrm{~s}^{-1}$. Relative humidity was kept between 60 and $70 \%$.

\section{Plant and nodule harvesting}

For further analysis, nodules from at least 15 plants from four independent experiments $(n \geq 60)$ were excised from roots 3 weeks post-inoculation. At this age, relative shoot and root fresh weight of -B plants were only $40 \%$ of the control, and nodule size and number were significantly reduced (data not shown) as described in previous papers (Redondo-Nieto et al. 2001, 2003). In previous experiments, we demonstrated that 3-week-old control nodules were fully functional, while nodules from $-\mathrm{B}$ plants showed a $70 \%$ reduction of nitrogen-fixing (acetylene reduction) activity, resulting in plants suffering from $\mathrm{N}$ deficiency (Bolaños et al. 1994). Therefore, the observed reduction in fresh weight was shown to be mainly caused by a lack of $\mathrm{N}$, and only in part to B deficiency.

For anti-leghaemoglobin $(\mathrm{Lb})$ staining, nodules were harvested at a stage of development 1, 2 (when -B plants still did not show any reduction of growth), 3 and 7 weeks post-inoculation (when plants reached the stage of senescence).

\section{Antibodies and antisera}

Monoclonal antibody MAC 265 recognizes an intercellular plant glycoprotein, which was first identified in the infection thread lumen (VandenBosch et al. 1989) and in the intercellular spaces of uninfected tissue or root nodules (Rae et al. 1991), and which was characterized as a legume-specific arabinogalactan-extensin (AGPE) by Rathbun, Naldrett \& Brewin (2002). MAC 57 recognizes a constitutive epitope associated with the $\mathrm{O}$-antigen component of the lipopolysaccharide (LPS) of $R$. leguminosarum 3841 (Brewin et al. 1986). Monoclonal MAC 203 antibody recognizes an epitope expressed on the LPS of strain 3841 when grown at low $\mathrm{O}_{2} /$ low pH (Kannenberg \& Brewin 1989) and in $\mathrm{N}_{2}$-fixing bacteroids (Kannenberg et al. 1994), but is absent under high $\mathrm{O}_{2}$ concentrations. Antiserum anti-RGII 
recognizes cell wall rhamnogalacturonan II pectin polysaccharide (Matoh et al. 1998). Antiserum anti-Lb (Govers et al. 1985) was used for Lb detection. Antiserum anti-ascorbate peroxidase (APX) was raised against Glycine max nodule cytosolic APX (Dalton et al. 1993).

\section{Fractionation of nodules}

Pea nodules ( $1.5 \mathrm{~g}$ fresh weight) were homogenized at $4{ }^{\circ} \mathrm{C}$ in Tris-dithiothreitol buffer (50 mM Tris- $\mathrm{HCl}, \mathrm{pH} 7.5$, $10 \mathrm{mM}$ dithiothreitol) containing $0.5 \mathrm{M}$ sucrose. The homogenates were filtered through Miracloth (Calbiochem, Madrid, Spain) and centrifuged for $30 \mathrm{~min}$ at $10000 \mathrm{~g}$. The resulting supernatant was defined as the nodule soluble fraction. The resulting pellet contained the symbiosome and bacteroid fractions. The bacteroids still enclosed by the peribacteroid membrane were prepared by fractionation into bacteroid, membrane and peribacteroid fluid, and then purified by centrifugation through a sucrose gradient according to Brewin et al. (1985).

\section{In vitro binding to B-chelating-specific resin and immunoassays}

Aliquots ( $1 \mathrm{~mL}$ ) of nodule extracts, containing $1.5 \mu \mathrm{g}$ protein $\mu \mathrm{L}^{-1}$, as determined according to Bradford (1976), were incubated for $1 \mathrm{~h}$ at $4{ }^{\circ} \mathrm{C}$ with $0.5 \mathrm{~g}$ of the B-binding-specific resin Amberlite IRA-743 (Sigma Chemical Co.), which strongly complexes boric acid and borate anions on its $\mathrm{N}$-methylglucamine functional groups with an adsorption capacity of up to $5 \mathrm{mg} \mathrm{B} \mathrm{g}^{-1}$ resin (Asad et al. 1997). Before use, the resin was cleaned following the procedure described by those authors. After incubation, the mixture was centrifuged for $1 \mathrm{~min}$ at $10000 \mathrm{~g}$, and washed 14 times with Tris-dithiothreitol buffer. The supernatants not associated with the resin and the pellets resulting from washes were boiled for $10 \mathrm{~min}$ at $100{ }^{\circ} \mathrm{C}$ in Laemmli buffer containing $10 \%$ SDS. After centrifugation to remove resin and insoluble debris, the solubilized material was separated following sodium dodecyl sulphate-polyacrylamide gel electrophoresis (SDS-PAGE) with 12\% polyacrylamide resolving gels (Laemmli 1970), and was silver stained for protein detection. Replicate gels were electrophoretically transferred to membranes of nitrocellulose, and were incubated with $5 \%$ bovine serum albumin in TBS (50 mM Tris- $\mathrm{HCl}, \mathrm{pH} 7.4,200 \mathrm{mM} \mathrm{NaCl}$ ) buffer containing an antibody. Immunostaining was visualized using a goat anti-rat IgG (for monoclonal antibodies) or a goat anti-rabbit IgG (for antiserum) peroxidase-conjugated secondary antibody (Bradley et al. 1988).

Experiments were repeated using the anion exchange Dowex 1-X8 resin (Bio-Rad Laboratories, Hercules, CA, USA) following the same experimental procedures to detect non-specific binding.

\section{Microscopy on nodule sections}

Three-week-old pea nodules developed in the presence or in the absence of B were fixed overnight at $4{ }^{\circ} \mathrm{C}$ in $2.5 \%$ (v/v) glutaraldehyde in $0.1 \mathrm{M}$ sodium cacodylate buffer, $\mathrm{pH}$ 7.2. The nodules were dehydrated in an ethanol series and embedded in LR-White resin (London Resin Company, London, UK). Semithin $(0.5 \mu \mathrm{m})$ sections were processed for immunogold staining and silver enhancement as described previously (Perotto et al. 1991). Additionally, ultrathin (silvery gold in colour) sections of nodules were processed for immunogold staining following transmission electron microscopy according to methods previously described (Rae et al. 1991). A goat anti-rat IgG-colloidal gold (10 nm gold particles) (Amersham, Little Chalfont, Bucks, UK) was used as a secondary antibody to reveal MAC 265 labelling. Controls without the first antibody to identify background staining were included (not shown).

\section{RNA extraction and RT-PCR}


Total RNA was extracted from both control and B-deficient nodules harvested 1, 2 and 3 weeks post-inoculation and frozen in liquid nitrogen. Nodules (approximately $250 \mathrm{mg}$ ) were ground with a mortar and pestle, and RNA was prepared with an RNA extraction kit (ARN SV Total RNA Isolation System; Promega, Madison, WI, USA). RNA concentration and quality were determined by absorption at 260, 280 and $230 \mathrm{~nm}$ with a Biophotometer Eppendorf (Hamburg, Germany), and integrity was estimated by the contents of ribosomal RNA in ethidium bromide-stained formaldehyde-denaturing gels. Equal amounts of RNA (75 ng) from control and B-deficient tissues were subjected to RT-PCR in a single-tube assay according to the manufacturer's instructions (AccessQuick RT-PC System, Promega) using the following primers $L b-5^{\prime}$ (5'-GGGTTTTACTGATAAACAAG-3'); Lb-3' (5'-CATTGCCTTCTTAATTGCG3'); $M s c 27-5^{\prime}$ (5'-GGAGGTTGAGGGAAAGTGG-3') and Msc27-3' (5'-CACCAACAA AGAATTGAAGG-3').

\section{In gel APX activity staining and immunodetection}

Homogenized 3-week-old nodules ( $100 \mathrm{mg}$ ) were mixed with $1 \mathrm{~mL}$ cold extraction buffer composed of $100 \mathrm{mM}$ potassium phosphate buffer, $\mathrm{pH} 7.0 ; 5 \mathrm{mM} \mathrm{Na-EDTA;} \mathrm{0.1 \%} \mathrm{Triton} \mathrm{X-100;} 10 \mathrm{mM}$ ascorbate; and $1 \mu \mathrm{L}$ protease inhibitor cocktail Sigma P2714. After centrifugation, the solubilized proteins (20 $\mu \mathrm{g}$ per well) were loaded onto $10 \%$ resolving polyacrylamide gels without SDS previously equilibrated in running buffer ( $25 \mathrm{mM}$ Tris- $\mathrm{HCl}(\mathrm{pH} 8.3)$, $200 \mathrm{mM}$ glycine, $2 \mathrm{mM}$ ascorbate) for $30 \mathrm{~min}$ at $60 \mathrm{~V}$, and electrophoresis was performed in cold at $80 \mathrm{~V}$ for $15 \mathrm{~min}$, $100 \mathrm{~V}$ for $30 \mathrm{~min}$ and $120 \mathrm{~V}$ for $1 \mathrm{~h}$. APX activity was visualized by negative staining with nitroblue tetrazolium (Mittler \& Zilinskas 1993). Alternatively, replicate gels were electroblotted to nitrocellulose sheets for immunostaining, as previously described.

\section{Reproducibility}

All experiments were repeated at least four times with a sample size of $n \geq 15$ nodulated plants per experiment.

\section{RESULTS}

Pea plants grown in the presence $(+\mathrm{B})$ or absence $(-\mathrm{B})$ of $\mathrm{B}$ were inoculated with R. leguminosarum bv viciae 3841. Fractions derived from nodule homogenates were incubated with B-binding specific resin Amberlite IRA-743 to capture borate and nodule-derived biomolecules linked to it (see Materials and methods for details). Following SDSPAGE and silver staining of solubilized material associated with the resin beads (Fig. 1), several bands were visible in extracts from $+\mathrm{B}$ nodules corresponding to the soluble fraction obtained after centrifugation of nodule homogenates (Fig. 1, lane 3). However, only very weak bands were detected in extracts derived from -B nodules (Fig. 1, lane 4). When nodule extracts were incubated with Dowex resin beads in order to detect non-specific binding, no bands were observed (Fig. 1, lanes 7 and 8).

Antibodies that recognize components involved in nodule development were used to detect the presence of these components in the Amberlite-binding fraction. Glycoprotein antigens recognized by the MAC 265 antibody (legumespecific AGPE) (Fig. 2a) were present to a similar extent in $+B$ and $-B$ nodule homogenates (Fig. 2a, lanes $5+6$ ). While these antigens were strongly associated with Amberlite in extracts obtained from $+\mathrm{B}$ nodules (Fig. 2a, lane 1), they were only weakly associated with the resin in extracts derived from-B nodules (Fig. 2a, lane 3). A MAC 265 staining of very low intensity (lower than shown in Fig. 2a, lane 3) was detected in the fraction associated with Dowex 
resin, irrespective of the B supply (Fig. 2a, lanes 7 and 8). To test whether the binding capacity of AGPE to Amberlite resin was caused by the presence of $\mathrm{B}$, soluble fractions from nodule extracts were incubated $\left(1 \mathrm{~h}\right.$ at $\left.4{ }^{\circ} \mathrm{C}\right)$ in vitro with buffers containing $10 \mathrm{mM}$ borate prior to exposure to the resin-binding assays. Under these conditions, AGPE derived from -B nodule extracts pre-incubated with borate was strongly associated with Amberlite (Fig. 2a, lane 10). The intensity of staining was similar to that of extracts derived from + B nodules (Fig. 2a, lane 9).

The use of an antibody against $\mathrm{Lb}$ (Fig. 2b) allowed the identification of a band of approximately $16 \mathrm{kDa}$ apparent molecular mass associated with Amberlite (Fig. 1, arrow; and Fig. 2b, lane 1). This protein band was neither detected in -B nodules (Fig. 1, lane 3; and Fig. 2b, lane 2) nor was it found to be associated with the Dowex resin (Fig. 1, lanes 7 and 8). Immunodetection of RGII was included as evidence that the Amberlite resin was able to bind borate complexes (Fig. 2c). RGII was retained by the Amberlite resin only in homogenates derived from + B nodules, but not from - B nodules (Fig. 2c, lanes 1 + 2). Additional assays with other antibodies that recognize bacterial LPSs, or other plant membrane-bound or soluble glycoproteins and glycolipids involved in nodule development gave negative results. These antibodies included MAC 206, which recognizes carbohydrate epitopes associated with glycolipids or with a lipid-anchored AGP; MAC 207 recognizing carbohydrates of plant membrane glycoproteins; MAC 254 that reacts with carbohydrate epitopes associated with glycoproteins that are targeted to the peribacteroid fluid (Perotto et al. 1991); antiserum R76, which reacts with the lectin-like PsNLEC-1 (Dahiya, Kardailsky \& Brewin 1997); or MAC 57 which recognizes an epitope associated with the LPS of $R$. leguminosarum 3841 (Brewin et al. 1986) (data not shown). Therefore, further investigations were focused on AGPE tissue distribution and Lb occurrence.

Immunogold labelling of semithin or ultrathin nodule sections (Fig. 3) showed that the MAC 265 antibody labelled infection threads of both + B (Fig. 3a) and - B (Fig. 3b) nodules, although a lower number of stained threads was visible in the $-\mathrm{B}$ treatments (highlighted by arrows). The cell walls and intercellular spaces of the parenchyma of $+\mathrm{B}$ nodules reacted strongly with MAC 265 (Fig. 3c,e). However, labelling was reduced in the cell walls and intercellular spaces of the cortex in B-deficient nodules (Fig. 3d,f).

The occurrence of $\mathrm{Lb}$ during nodule development was investigated in extracts derived from $+\mathrm{B}$ and $-\mathrm{B}$ nodules harvested weekly after inoculation with Rhizobium. Immunoblots showed that Lb was detected as early as 1 week after inoculation (Fig. 4, lanes 1 and 2) in both + B and - B nodules. However, whereas Lb was always detectable in + B nodules throughout development (Fig. lanes 1, 3, 5, 7), it disappeared from B-deficient nodules 2 weeks after inoculation (Fig. 4, lanes 2, 4, 6, 8). To confirm whether the disappearance of Lb was caused by a transcriptional or post-transcriptional effect, $\mathrm{Lb}$ gene expression was studied using RT-PCR of total nodule RNA. The mRNA of Lb was always present both in $+B$ - and -B-treated plants, with an expression peak 2 weeks after inoculation (Fig. 5). Although a decline of gene expression was observed in -B nodules between 2 and 3 weeks after inoculation, it could not explain the total loss of $\mathrm{Lb}$ antigen as seen in Fig. 4.

Because both AGPE and $\mathrm{Lb}$ are involved in the regulation of nodule oxygen $\left(\mathrm{O}_{2}\right)$ concentration, we used MAC 203 antibody as a probe for micro-aerobic conditions inside the nodule. MAC 203 recognizes an LPS epitope expressed in R. leguminosarum 3841 only when grown at low $\mathrm{O}_{2}$ or low $\mathrm{pH}$ (Kannenberg \& Brewin 1989), and in bacteroids localized to the micro-aerobic zone of $\mathrm{N}_{2}$ fixation (Kannenberg et al. 1994). Immunostaining with MAC 203 antibody revealed labelling of purified bacteroid extracts derived from + B nodules (Fig. 6a, lane 1), but not from $-\mathrm{B}$ nodules (Fig. 6b, lane 2). As a control for loading, Fig. 6b shows immunostaining with MAC 57, which recognizes a constitutive epitope on the LPS of strain 3841. 
Changes in oxygen concentrations could result in the formation of reactive oxygen species (ROS). In order to test whether -B nodules were damaged by ROS, we determined the contents of lipid peroxides (malondialdehyde) and oxidized proteins (total carbonyl groups). However, we could not detect any difference in these two parameters between $+\mathrm{B}$ and $-\mathrm{B}$ nodules (data not shown). The activity of APX, a key antioxidant enzyme of nodules, was studied in nodule homogenates (Fig. 7). Immunostaining with an antibody raised against soy bean cytosolic APX was more intense in extracts from $+B$ nodules than in those from $-B$ nodules (Fig. 7a). Moreover, in-gel analysis of APX activity (Fig. $7 b$ ) revealed that the activities of all isoforms detected were greater in $+B$ than in $-B$ nodules.

\section{DISCUSSION}

The development of the symbiosis between legumes and rhizobia, resulting in $\mathrm{N}_{2}$-fixing nodules, is significantly impaired by B deficiency. Using a resin, which strongly complexes $\mathrm{H}_{3} \mathrm{BO}_{3}$ on its $N$-methyl glucamine functional groups (Asad et al. 1997), we have been able to detect (Fig. 1) and identify (Fig. 2) potential borate ligands that could partially explain the effects of B deprivation on nodule development. Cell wall pectin polysaccharide RGII (Fig. 2c), a secreted glycoprotein identified by MAC 265 antibody (Fig. 2a), and the oxygen carrier Lb (Fig. 2b) showed a significant capacity to associate with Amberlite B-specific resin when they were extracted from nodules developed in the presence, but not from those developed in the absence of B. Because neither of these nodule components significantly associated with Dowex resin, and because Amberlite resin has been described to bind specifically to borate and boric acid under a range of conditions (Kunin \& Preuss 1964), it can be postulated that the interaction of nodule components with Amberlite is caused by borate or to a borate ligand associated with these molecules. It should be kept in mind that our approach can only detect borate monoesters, because two-sided complexes have 'occupied' all borate sites able to bind to Amberlite. Whether such borate monoesters have a physiological importance is still under debate (Godbach \& Wimmer 2007). It is possible, that some of the detected borate ligands are intermediate products formed during the process of borate cross-link formation.

All of the components identified in the present study are either secreted or cytosolic macromolecules. Previously, some effects of B deficiency on nodule development, including symbiosome differentiation and nodule organogenesis, have been related to the stability of membrane glycoproteins (so-called RGII glycoproteins because they reacted with anti-RGII antibody) (Redondo-Nieto et al. 2007). In our experimental approach, we have not been able to identify these membrane glycoproteins in the Amberlite-binding fraction, likely because of poor extraction of membrane proteins during nodule fractionation. Because several studies on B effects in plant and animal development, and metabolism point to roles of B in/for membrane functions (Brown et al. 2002), our approach has to be complemented with other procedures to detect membrane-bound complexes of borate, such as those reported by Wimmer et al. (2009).

Throughout each step of root nodule development in leguminous plants, an intense cell wall remodelling takes place (Brewin 2004). Therefore, nodules are also excellent organs for investigating structural roles of B. Typical symptoms of B deficiency in root nodules are enlarged and irregularly shaped walls with several components abnormally assembled. Nodules devoid of B have cell walls without covalently bound hydroxyproline-/proline-rich glycoproteins (Bonilla et al. 1997), and show changes in the content and distribution of pectic polysaccharides (Redondo-Nieto et al. 2003, 2007). In our experiments, a fraction containing RGII extracted from +B nodules was able to associate with Amberlite (Fig. 2c, lane 1), while another fraction remained unassociated (Fig. 2c, lane 3). In our opinion, there are 
two possible explanations for these observations: either a fraction of RGII is present as monomeric B-RGII ester (e.g. as an intermediate during cell wall formation) or B might form one-sided (B-RGII) complexes with other sugar moieties of the RGII molecule, which are able to associate with Amberlite. The fact that RGII extracted from $-\mathrm{B}$ nodules did not bind to Amberlite (Fig. 2c, lane 2) suggests that one-sided B-RGII complexes were missing under these conditions. These results are in line with a possible function of B in stabilization and anchoring of cell wall pectin intermediates and other structural (glyco)-proteins, as suggested in Findeklee \& Goldbach (1996).

Besides the effects on nodule cell wall structure, B deficiency affects nodule occupancy, leading to poorly invaded nodules (Bolaños et al. 1996; Redondo-Nieto et al. 2001). Following nodule development, rhizobia invade the plant by division and growth through a transcellular tunnel (the infection thread) sheathed with cell wall material, and by an endocytosis-like process from unwalled infection droplets (Brewin 1991). Within the threads, rhizobia are embedded in intercellular plant-derived matrix material, including a highly glycosylated legume-specific protein characterized as AGPE or root nodule extensin (RNE) (Rathbun et al. 2002). AGPEs are secreted by legume cells into the lumen of the infection thread as an early response to rhizobial infection (Vandenbosch et al. 1989; Rae, Bonfante-Fasolo \& Brewin 1992). Inwards apical growth of infection threads may be driven by peroxide-driven tyrosine cross-linking of AGPE (Wisniewski et al. 2000) that promotes fluid-to-solid transition of the infection thread matrix, and inhibits or reduces bacterial division. Following hardening, polar growth occurs by secretion of new AGPE at the thread apex in a fluid state that allows bacterial growth (Brewin 2004). Using MAC 265 antibody to detect AGPE, we have shown that B deficiency led to poor development of infection threads in pea nodules (Fig. 3b). Apparently, the absence of B did not reduce AGPE glycoprotein production, because the amount of AGPE extracted from $+B$ or $-\mathrm{B}$ nodules was similar or even higher in $-\mathrm{B}$ nodule homogenates (Fig. 2a, lanes 5 and 6). However, the capacity to bind to Amberlite was significantly reduced under -B conditions (Fig. 2a, lane 3), but could be partially re-established by treatment of the extracted homogenates with $10 \mathrm{mM} \mathrm{B}$ (Fig. 2a, lanes 9 and 10). These results indicate that the presence of B was necessary to promote the capacity of AGPE to associate to the Amberlite fraction. The very weak capacity of AGPEcontaining fractions derived from -B nodules to bind to Amberlite (Fig. 2a, lane 3), which was comparable to binding to the Dowex resin (Fig. 2a, lanes 7 and 8), is likely caused by its capacity to adhere to negatively charged surfaces (Rathbun et al. 2002). Therefore, these results indicate that AGPE is indeed able to interact with borate or with borate complexes, and suggest that this association is important for infection thread growth.

In addition to their presence in the lumen of infection threads, AGPEs are also secreted to the intercellular spaces of uninfected tissues (Rae et al. 1991), where they are involved in the mechanisms of regulation of the oxygen diffusion barrier (Iannetta et al. 1993). Detection, following immunostaining with MAC 203, of an LPS antigen induced under low oxygen is indicative of a micro-aerobic environment inside + B nodules (Fig. 6a, lane 1), while low MAC 203 staining of bacteroids derived from -B nodules (Fig. 6a, lane 2) suggests a high oxygen concentration, and therefore, a malfunctioning oxygen barrier under B deficiency. The reduction of MAC 265 antigens in intercellular spaces of uninfected nodule parenchyma observed under B deficiency (Fig. 3c-f) suggests that oxygen could diffuse through spaces not sealed with AGPEs in the -B nodule cortex (Fig. 3d,f). The potential capacity of AGPE to bind to B or borate complexes, shown in Fig. 2, may be linked to the stability of the oxygen diffusion barrier. Under B deficiency, the absence of RGII bound to borate led to structural alterations of the cell wall that reduced wall elasticity (Findeklee \& Goldbach 1996) and increased cell wall porosity (Fleischer, O'Neil \& Ehwald 1999), and such changes may also allow higher rates of oxygen diffusion. At the same time, the lack of association of AGPE to the borate-pectic network in B-deficient nodules could de-stabilize the extracellular matrix of the nodule cortex as suggested by Fig. $3 \mathrm{~d}$,f, and 
could reduce intercellular adhesion. Actually, pectins (Lord \& Mollet 2002), and particularly the formation of the dimer B-RGII, are important for cell-to-cell adhesion (Iwai et al. 2002).

Besides RGII and AGPE, $\mathrm{Lb}$ is also associated with Amberlite. Lb is a non-glycosylated protein, but borate is able to interact with aminoacyl residues such as hydroxyl groups of serine or threonine, or amine groups of arginine, as described for the bacterial quorum sensor AI2 (Chen et al. 2002) and likely for the boronic acid-mediated inhibition of serine proteases (Kettner \& Shenvi 1984). Additionally, it was also reported that B forms covalent bonds with amine groups near the coordination Fe site of the oxygen carrier hemerythrin of Golfingia gouldii (Garbett, Darnall \& Klotz 1971). Therefore, it would be interesting to test the possibility of covalent binding of B with Lb and other heme oxygen carriers, and whether this could have a physiological importance. Our results also show that B deficiency induces a loss of $\mathrm{Lb}$ during the development of B-deficient pea nodules (Figs $2 \mathrm{~b} \& 4$ ). A reduction of Lb gene expression was also observed under B deficiency (Fig. 5), but was insufficient to explain the detected total loss of Lb. Therefore, B seems to be essential at a post-transcriptional level for maintaining the stability of Lb proteins. Whether this is directly related to borate binding or is caused by the induction of protease activity during nodule development under B deficiency still has to be tested.

Loss of oxygen regulation could result in oxidative damage to B-deficient nodules. Actually, it has been reported that death of B-deprived cells was caused by oxidative stress (Koshiba, Kobayashi \& Matoh 2009). However, the content of lipid peroxides or carbonyl groups was not increased in B-deficient as compared to B-sufficient pea nodules (data not shown). Furthermore, one of the major antioxidative enzymes in nodules, the APX (reviewed by Matamoros et al. 2003), was reduced both at the protein and the activity levels in -B nodules (Fig. 7), suggesting that ROS production was lower in nodules developed without B compared to those developed with B. This is contradictory to other reports indicating an increase in ROS production under -B conditions (Koshiba et al. 2009). It has been demonstrated that Lb contributes significantly to ROS generation in functional nodules, and that ROS metabolism is attenuated in Lbdeficient nodules (Günther et al. 2008). Loss of Lb in B-deficient nodules would then account for a reduced oxidative damage. Moreover, another significant process that generates ROS in nodules, the high rates of bacteroid respiration (Becana et al. 2000), is maintained by Lb (Appleby 1984), and consequently bacteroid respiration should be significantly decreased in B-deficient nodules which are poorly colonized by bacteroids. This would explain, why in the legume nodule model, $-\mathrm{B}$-induced ROS production could be overcompensated by the reduction in Lb-induced ROS production, while B-deficient tobacco cells were severely damaged and ultimately killed by ROS under B deficiency (Koshiba et al. 2009).

Overall, we conclude that B deficiency led to the development of non-functional nodules by affecting properties and stability of potential borate ligands involved in bacterial infection and oxygen regulation, but apparently without inducing oxidative stress.

\section{ACKNOWLEDGEMENTS}

We thank Dr M. Becana (Estación Experimental de Aula Dei, CSIC, Zaragoza, Spain) for helpful discussion and comments during manuscript preparation, and for kindly providing anti-Lb and anti-APX antisera. MAC 265 was kindly provided by Dr N. J. Brewin (John Innes Centre, Norwich, UK), and anti-RGII was kindly supplied by Dr T. Matoh (University of Kyoto, Kyoto, Japan). This work was supported by Ministerio de Educación y Ciencia, 
BIO2008-05736-CO2-01 and by MICROAMBIENTECM Program from Comunidad de Madrid. M.R. is the recipient of a contract from Comunidad de Madrid.

\section{REFERENCES}

- $\quad$ Appleby C.A. (1984) Leghemoglobin and Rhizobium respiration. Annual Reviews of Plant Physiology and Plant Molecular Biology 35, 443-478.

- $\quad$ Asad A., Bell R.W. \& Huang L. (1997) Development of a boron buffered solution culture system for controlled studies of plant boron nutrition. Plant and Soil 188, 21-32.

- $\quad$ Becana M., Dalton D.A., Moran J.F., Iturbe-Ormaetxe I., Matamoros M.A. \& Rubio M.C. (2000) Reactive oxygen species and antioxidants in legume nodules. Physiologia Plantarum 109, 372-381.

- $\quad$ Bell R.W., Dell B. \& Huang L. (2002) Boron requirements of plants. In Boron in Plant and Animal Nutrition (eds H.Goldbach, B.Rerkasem, M.A.Wimmer, P.H.Brown, M.Thellier \& R.W.Bell), pp. 63-86. KluwerAcademic/Plenum Publishers, New York, NY, USA.

- $\quad$ Beringer J.E. (1974) $R$ factor transfer in Rhizobium leguminosarum. Journal of General Microbiology 84, $188-198$.

- Bolaños L., Esteban E., De Lorenzo C., FernánDez-Pascual M., De Felipe M.R., Gárate A. \& Bonilla I. (1994) Essentiality of boron for symbiotic dinitrogen fixation in pea (Pisum sativum)-Rhizobium nodules. Plant Physiology 104 , 85-90.

- Bolaños L., Brewin N.J. \& Bonilla I. (1996) Effects of boron on Rhizobium-legume cell-surface interactions and nodule development. Plant Physiology 110, 1249-1256.

- Bolaños L., Cebrián A., Redondo-Nieto M., Rivilla R. \& Bonilla I. (2001) Lectin-like glycoprotein PsNLEC-1 is not correctly glycosylated and targeted in boron deficient pea nodules. Molecular Plant-Microbe Interactions 14, 663-670.

- Bolaños L., Lukaszewski K., Bonilla I. \& Blevins D. (2004) Why boron? Plant Physiology and Biochemistry 42, 907912.

- Bonilla I., Mergold-Villaseñor C., Campos M.E., Sánchez N., Pérez H., López L., Castrejón L., Sánchez F. \& Cassab G.I. (1997) The aberrant cell walls of boron-deficient bean root nodules have no covalently bound hydroxyprolin/proline-rich proteins. Plant Physiology 115, 1329-1340.

- Bradford M. (1976) A rapid and sensitive method for the quantitation of microgram quantities of protein utilizing the principle of protein-dye binding. Analytical Biochemistry 72, 248-254.

- $\quad$ Bradley D.J., Wood E.A., Larkins A.P., Galfre G., Buchter G.W. \& Brewin N.J. (1988) Isolation of antibodies reacting with peribacteroid membranes and other components of pea root nodules containing Rhizobium leguminosarum. Planta $173,149-160$.

- Brewin N.J. (1991) Development of the legume root nodule. Annual Review of Cell Biology 7, 191-226.

- Brewin N.J. (2004) Plant cell wall remodelling in the Rhizobium-legume symbiosis. Critical Reviews in Plant Sciences 23, 293-316.

- $\quad$ Brewin N.J., Robertson J.G., Wood E.A., Wells B.A., Larkins A.P., Galfre G. \& Butcher G.W. (1985) Monoclonal antibodies to antigens in the peribacteroid membrane from Rhizobium-induced root nodules of pea-cross-react with plasma membrane and Golgi bodies. EMBO Journal 4, 605-611.

- Brewin N.J., Wood E.A., Larkins A.P., Galfre G. \& Butcher G.W. (1986) Analysis of lipopolysaccharides of Rhizobium leguminosarum using monoclonal antibodies. Journal of General Microbiology 132, 1959-1966.

- $\quad$ Brown P.H., Bellaloui N., Wimmer M.A., Bassil E.S., Ruiz J., Hu H., Pfeffer H., Dannel F. \& Römheld V. (2002) Boron in plant biology. Plant Biology 4, 205-223.

- Chen X., Schauder S., Potier N., Van Dorsselaer A., Pelczer I., Bassier B.L. \& Hughson F.M. (2002) Structural identification of a bacterial quorum-sensing signal containing boron. Nature 415, 545-549.

- Dahiya P., Kardailsky I.V. \& Brewin N.J. (1997) Immunolocalization of PsNLEC-1, a lectin-like glycoprotein expressed in developing pea nodules. Plant Physiology 115, 1431-1442.

- $\quad$ Dalton D.A., Baird L.M., Langeberg L., Taugher C.Y., Anyan W.R., Vance C.P. \& Sarath G. (1993) Subcellular localization of oxygen defense enzymes in soybean (Glycine max [L.] Merr.) root nodules. Plant Physiology 102, 481489.

- Fahraeus G. (1957) The infection of clover root hairs by nodule bacteria studied by a simple glass technique. Journal of General Microbiology 16, 374-381. 
- $\quad$ Findeklee P. \& Goldbach H.E. (1996) Rapid effects of boron deficiency on cell wall elasticity modulus in Cucurbita pepo roots. Botanical Acta 109, 463-465.

- $\quad$ Fleischer A., O'Neil M.A. \& Ehwald R. (1999) The pore size of nongraminaceaous plant cell walls is rapidly decreased by borate ester cross-linking of the pectic polysaccharide rhamnogalacturonan II. Plant Physiology 121, 829-838.

- Garbett K., Darnall D.W. \& Klotz I.M. (1971) The effects of bound anions on the reactivity of residues in hemerythrin. Archives of Biochemistry and Biophysics 142, 455-470.

- Godbach H.E. \& Wimmer M.A. (2007) Boron in plants and animals: is there a role beyond RGII crosslinking? Journal of Plant Nutrition and Soil Science 170, 39-48.

- Govers F., Gloudemans T., Moerman M., Van Kammen A. \& Bisseling T. (1985) Expression of plant genes during the development of pea root nodules. EMBO Journal 4, 861-867.

- Günther C., Schlereth A., Udvardi M. \& Ott T. (2008) Metabolism of reactive oxygen species is attenuated in leghemoglobin-deficient nodules of Lotus japonicus. Molecular Plant-Microbe Interactions 20, 1596-1603.

- Hu H., Penn S.G., Lebrilla C.B. \& Brown P.H. (1997) Isolation and characterization of soluble B-complexes in higher plants. The mechanism of phloem mobility of boron. Plant Physiology 113, 649-655.

- Hunt C.D. (2007) Dietary boron: evidence for essentiality and homeostatic control in humans and animals. In Advances in Plant and Animal Boron Nutrition (eds F.Xu, H.E.Goldbach, P.H.Brown, R.W.Bell, T.Fujiwara, C.D.Hunt, S.Goldberg \& L.Shi), pp. 251-268. Springer, Dordrecht, the Netherlands.

- $\quad$ Iannetta P.P.M., De Lorenzo C., James E.K., Fernández-Pascual M.M., Sprent J.I., Lucas M.M., Witty J.F., De Felipe M.R. \& Minchin F.R. (1993) Oxygen diffusion in lupin nodules. I. Visualization of diffusion barrier operation. Journal of Experimental Botany 44, 1461-1467.

- Iwai H., Masaoka N., Ishii T. \& Satoh S. (2002) A pectin glucuronyltransferase gene is essential for intercellular attachment in the plant meristem. Proceedings of the National Academy of Sciences of the United States of America 99, $16319-16324$.

- Kannenberg E.L. \& Brewin N.J. (1989) Expression of a cell surface antigen from Rhizobium leguminosarum 3841 is regulated by oxygen and $\mathrm{pH}$. Journal of Bacteriology 171, 4543-4548.

- Kannenberg E.L. \& Brewin N.J. (1994) Host-plant invasion by Rhizobium: the role of cell-surface components. Trends in Microbiology 2, 277-283.

- Kannenberg E.L., Perotto S., Bianciotto V., Rathbun E.A. \& Brewin N.J. (1994) Lipopolysaccharide epitope expression of Rhizobium bacteroids as revealed by in situ immunolabelling of pea root nodule sections. Jornal of Bacteriology 176 , 2021-2032.

- Kettner C.A. \& Shenvi A.B. (1984) Inhibition of the serine proteases leukocyte elastase, pancreatic elastase, cathepsin-G, and chymotrypsin by peptide boronic acids. Journal of Biological Chemistry 259, 5106-5114.

- Koshiba T., Kobayashi M. \& Matoh T. (2009) Boron nutrition of tobacco BY-2 cells. V. Oxidative damage is the major cause of cell death induced by boron deprivation. Plant \& Cell Physiology 50, 26-36.

- $\quad$ Kunin R. \& Preuss A.F. (1964) Characterisation of a boron-specific ion exchange resin. Industrial \& Engineering Chemistry Products Research and Development 3, 304-306.

- $\quad$ Laemmli U.K. (1970) Cleavage of structural proteins during the assembly of the head of bacteriophage T4. Nature 227, $680-685$.

- $\quad$ Lord E.M. \& Mollet J.C. (2002) Plant cell adhesion: a bioassay facilitates discovery of the first pectin biosynthetic gene. Proceedings of the National Academy of Sciences of the United States of America 99, 15843-15845.

- Matamoros M.A., Dalton D.A., Ramos J., Clemente M.R., Rubio M.C. \& Becana M. (2003) Biochemistry and molecular biology of antioxidants in the rhizobia-legume symbiosis. Plant Physiology 133, 499-509.

- Matoh T., Takasaki M., Takabe K. \& Kobayashi M. (1998) Immunocytochemistry of rhamnogalacturonan II in cell walls of higher plants. Plant \& Cell Physiology 39, 483-491.

- $\quad$ Mittler R. \& Zilinskas B.A. (1993) Detection of ascorbate peroxidase activity in native gels by inhibition of the ascorbate-dependent reduction of nitroblue tetrazolium. Analytical Biochemistry 212, 540-546.

- $\quad$ O'Neill M.A., Eberhard S., Albersheim P. \& Darvill A.G. (2001) Requirement of borate cross-linking of cell wall rhamnogalacturonan II for Arabidopsis growth. Science 294, 846-849.

- Parr A.J. \& Loughman B.C. (1983) Boron and membrane function in plants. In Metals and Micronutrients: Uptake and Utilization by Plants (eds D.A.Robb \& W.S.Pierpoint), pp. 87-107. Academic Press, London, UK.

- $\quad$ Perotto S., VandenBosch K.A., Butcher G.W. \& Brewin N.J. (1991) Molecular composition and development of the plant glycocalyx associated with the peribacteroid membrane of pea root nodules. Development 112, 763-773.

- $\quad$ Rae A.L., Perotto S., Knox J.P., Kannenberg E.L. \& Brewin N.J. (1991) Expression of extracellular glycoproteins in the uninfected cells of developing pea nodule tissue. Molecular Plant-Microbe Interactions 4, 563-570. 
- $\quad$ Rae A.L., Bonfante-Fasolo I. \& Brewin N.J. (1992) Structure and growth of infection threads in the legume symbiosis with Rhizobium leguminosarum. The Plant Journal 2, 385-395.

- $\quad$ Ralston N.V.C. \& Hunt C.D. (2001) Diadenosine phosphates and S-adenosylmethionine: novel boron binding biomolecules detected by capillary electrophoresis. Biochimica et Biophysica Acta 1527, 20-30.

- Rathbun E.A., Naldrett M.J. \& Brewin N.J. (2002) Identification of a family of extensin-like glycoproteins in the lumen of Rhizobium-induced infection threads in pea root infection nodules. Molecular Plant-Microbe Interactions 15, 350359.

- $\quad$ Redondo-Nieto M., Rivilla R., El-Hamdaoui A., Bonilla I. \& Bolaños L. (2001) Boron deficiency affects early infection events in the pea-Rhizobium symbiotic interaction. Australian Journal of Plant Physiology 28, 819-823.

- $\quad$ Redondo-Nieto M., Wilmot A., El-Hamdaoui A., Bonilla I. \& Bolaños L. (2003) Relationship between boron and calcium in the $\mathrm{N}_{2}$-fixing legume-rhizobia symbiosis. Plant, Cell \& Environment 26, 1905-1915.

- $\quad$ Redondo-Nieto M., Pulido L., Reguera M., Bonilla I. \& Bolaños L. (2007) Developmentally regulated membrane glycoproteins sharing antigenicity with rhamnogalacturonan II are not detected in nodulated boron deficient Pisum sativum. Plant, Cell \& Environment 30, 1436-1443.

- $\quad$ Ricardo A., Carrigan M.A., Olcott A.N. \& Benner S.A. (2004) Borate minerals stabilize ribose. Science $303,196$.

- $\quad$ Shkolnik M.Y. (1984) Trace Elements in Plants. Elsevier, New York, NY, USA.

- VandenBosch K., Bradley D., Knox J., Perotto S., Butcher G. \& Brewin N.J. (1989) Common components of the infection thread matrix and the intercellular space identified by immunocytochemical analysis of pea nodules and uninfected roots. EMBO Journal 8, 335-342.

- Warington K. (1923) The effect of boric acid and borax on the broad been and certain other plants. Annals of Botany 37 , $629-672$.

- $\quad$ Wimmer M.A., Lochnit G., Bassil E., Mühling K.H. \& Goldbach H.E. (2009) Membrane-associated, boron-interacting proteins isolated by boronate affinity chromatography. Plant \& Cell Physiology 50, 1292-1304.

- $\quad$ Wisniewski J.P., Rathbun E.A., Knox J.P. \& Brewin N.J. (2000) Involvement of diamine oxidase and peroxidase in insolubilization of the extracellular matrix: implications for pea nodule initiation by Rhizobium leguminosarum. Molecular Plant-Microbe Interactions 13, 413-420.

- Wolf B. (1974) Improvement in the Azomethine H method for determination of boron. Communication in Soil Science Plant Analysis 5, 39-44 
Fig. 1

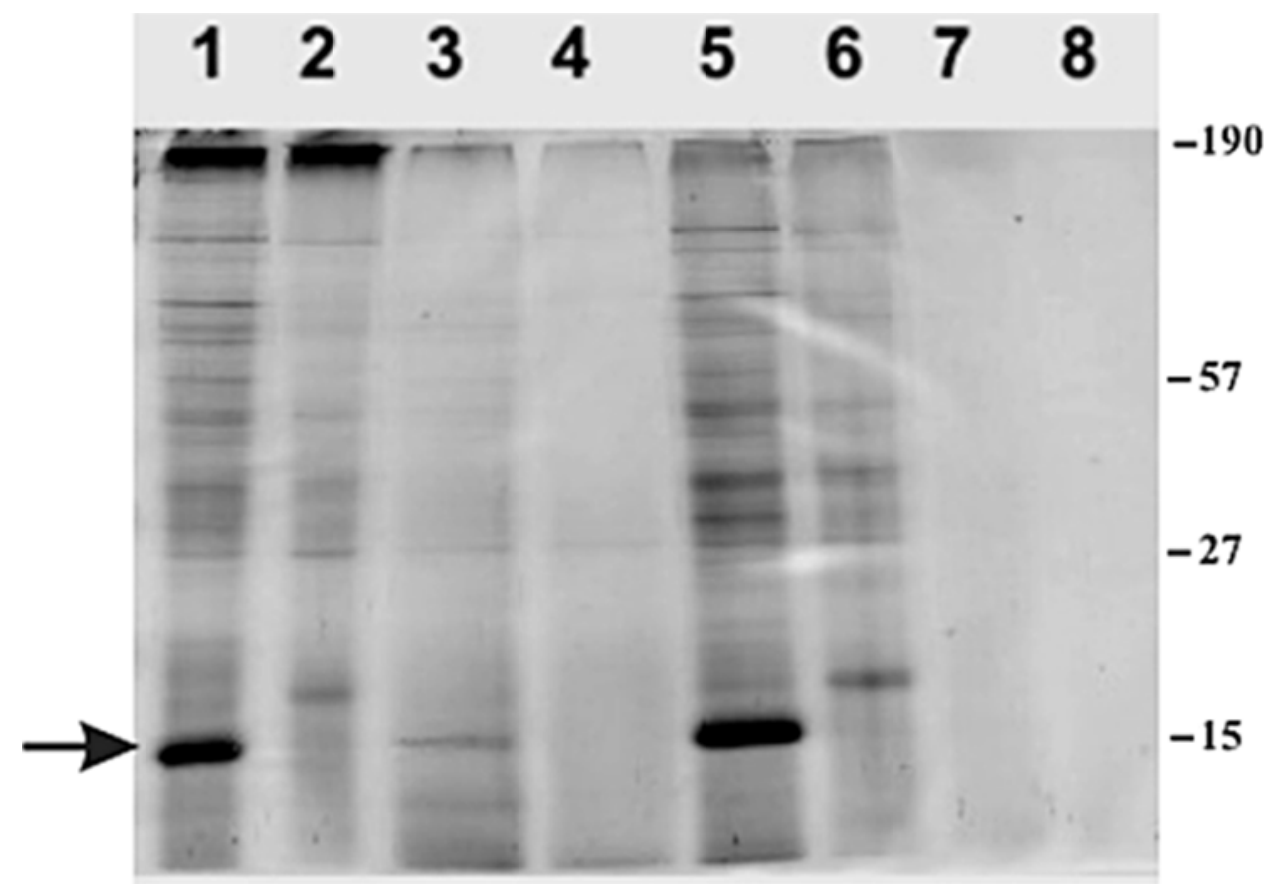

Fig. 2

(a)

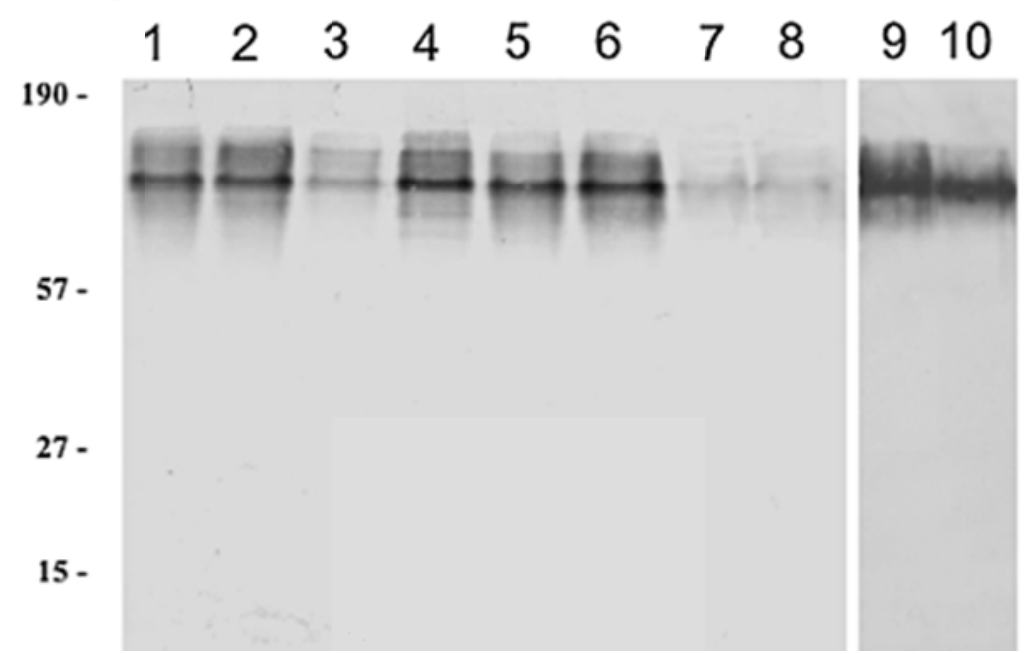

(b)

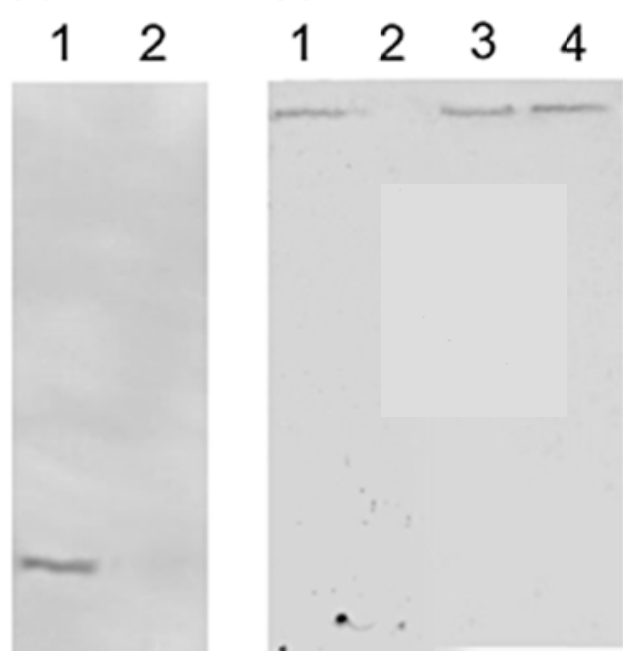


Fig. 3
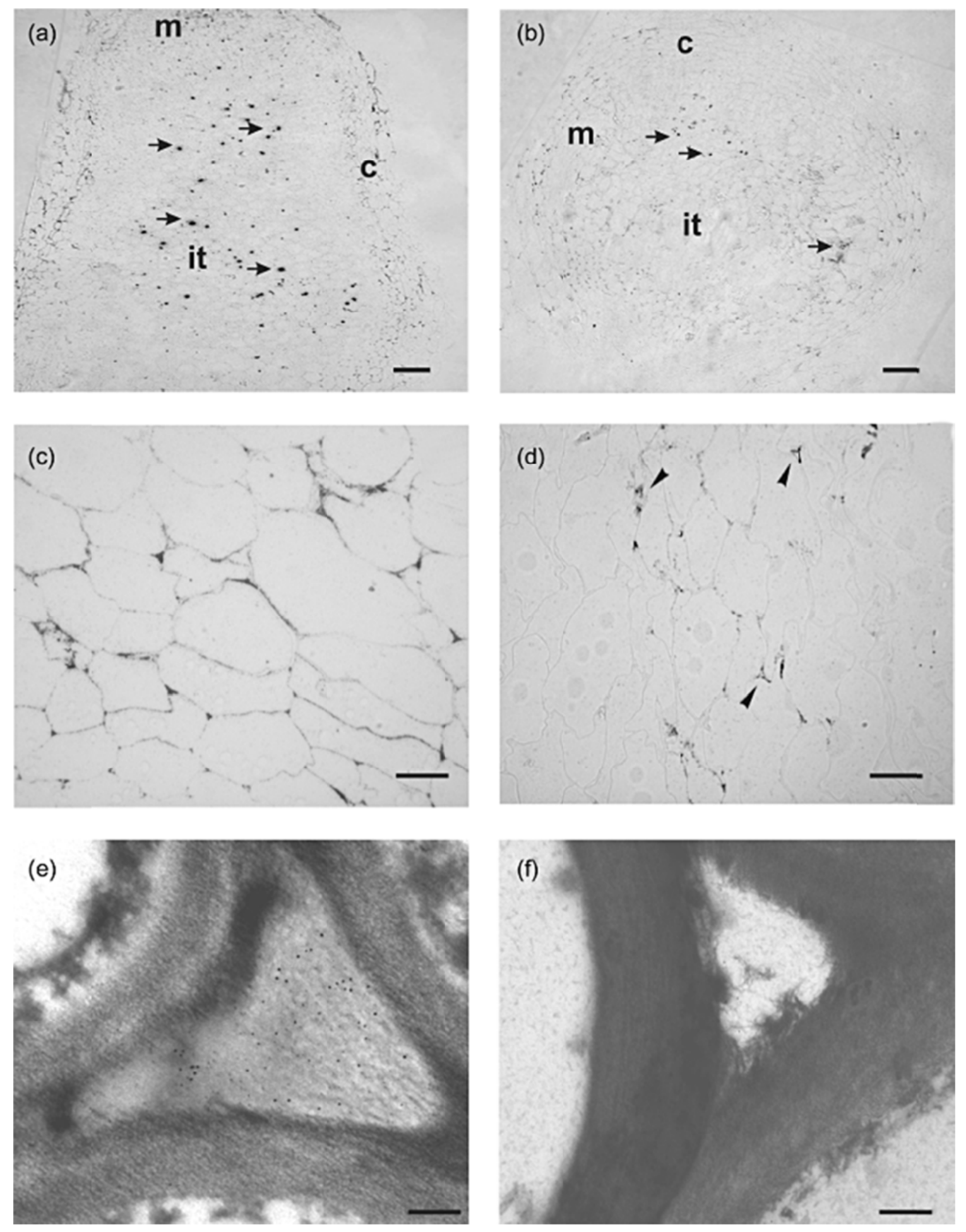
Fig. 4

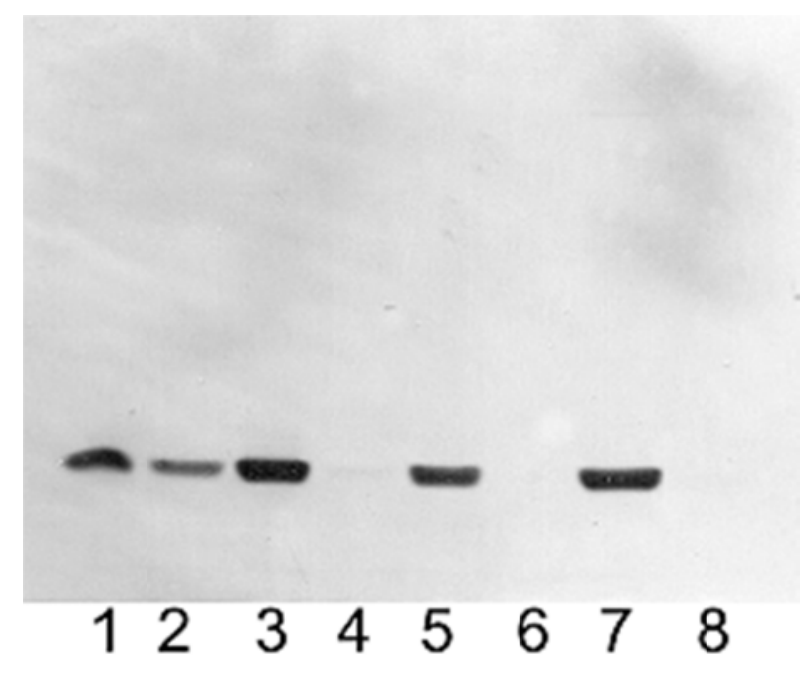

Fig. 5

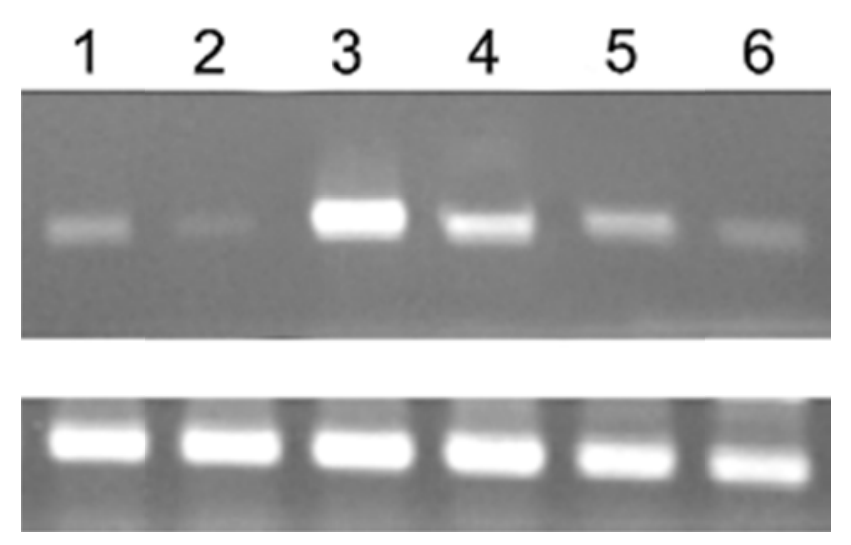


Fig. 6

(a)

(b)

12

12

Fig. 7

(a)

(b)

12

12

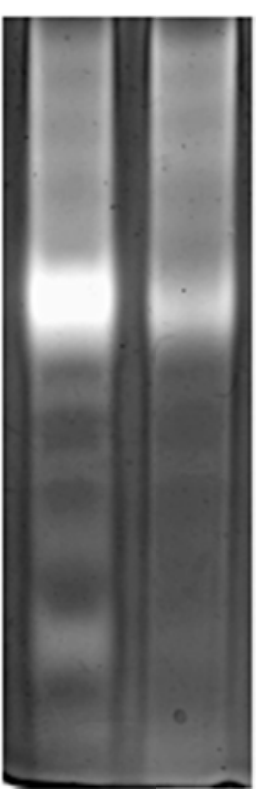

